\title{
PARTIDAS EPISTÉMICAS DE LOS ESTUDIOS CRÍTICO-LITERARIOS EN COSTA RICA
}

\author{
Carlos Manuel Villalobos
}

\begin{abstract}
RESUMEN
En este artículo se investiga el nacimiento de los estudios crítico-literarios en Costa Rica. Se estudia su aparición a finales del siglo XIX e inicios del XX. Se considera que la revisión de este género académico es relevante pues ofrece las claves operativas y las representaciones ideológicas que posibilitan entender los procesos de canonización y descatalogación de la literatura nacional. Se inicia con las primeras antologías poéticas de Costa Rica y la polémica nacionalista de 1894. Luego se consideran los primeros estudios estéticos publicados en el país. Entre los autores que participan destacan Antonio Zambrana, Moisés Vincenzi, Rafael Estrada, Justo Facio, Rogelio Sotela y Roberto Brenes Mesén. El idealismo croceano y el impresionismo crítico francés operan como códigos epistémicos orientadores. A esto se agregan los procesos de adaptación ideológica interna que le permite a la literatura operar como modelo educativo.
\end{abstract}

Palabras clave: Literatura costarricense, estudios críticos-literarios, idealismo croceano, impresionismo crítico francés.

\begin{abstract}
This article details the birth of the study of literary criticism in Costa Rica beginning with its appearance at the end of the nineteenth century through the beginning of the twentieth century. The "revision" of this academia genre is relevant because it offeres the operative key and the ideological representation that make posible the understanding of the process of canonization and the abandonment of Catholicism in the literature of the nation. It begins with the first anthologies of Costan Rican poetry and the national polemics of 1894. Then the author considers the first published esthetic studies of the country. The participating authors include: Antonio Zambrana, Moisés Vincenzi, Rafael Estrada, Justo Facio, Rogelio Sotela y Roberto Brenes Mesén. The "crocean" idealism and the French impressionists critique operate as orienting espitomological codes. From this are assigned the processes of internal ideological adaptation that facilitates the use of literature as an educational model.

Key words: Costa Rican Literature, study of literary criticism, "crocean" idealism, French impressionists critique.
\end{abstract}

Carlos Manuel Villalobos. Escuela de Filología, Lingüística y Literatura, Universidad de Costa Rica. San Pedro, San José, Costa Rica.

Correo electrónico: cmvillal@racsa.co.cr 


\section{Introducción}

Ningún discurso científico o académico es aséptico y menos cuando le corresponde la tarea de funcionar como agente catalogador de otros discursos. La crítica literaria es una de las prácticas discursivas que más obstáculos ideológicos debe superar para librarse del entusiasmo y las posturas axiológicas del crítico. Las mismas reglas que intervienen en la construcción del canon de los discursos literarios se aplican al crítico; tómese en cuenta, además, que la crítica funciona como apostilla semiótica del trabajo artístico (Picado 1983 y D'Alton 1990). De ahí que muchas veces opera como una muleta para echar a andar la invalidez de un texto literario. Otra veces, por el contrario, actúa como una camisa de fuerza que intenta anular la emergencia de nuevas epistemes transgresoras. De este modo, el discurso crítico se desempeña como uno de los instituyentes claves en los procesos de canonización y descatalogación de las obras artísticas. Es por ello que el estudio de las claves operativas y sus representaciones ideológicas son estratégicas para entender los procesos de legitimación en la historia de la literatura nacional.

Si se toma en cuenta que canon, etimológicamente, significaba una medida usada en carpintería, y que luego, por connotación, implicó norma (Sullá 1998: 19), resulta factible señalar que un sistema modélico de análisis literario es en sí un discurso canonizado y canonizante. Es decir, los discursos críticos diseñan sistemas canónicos que permiten medir y normar un discurso literario; pero, al mismo tiempo, estas estrategias analíticas participan de otras fuerzas que las aceptan o las rechazan. Hay programaciones científicas, políticas, económicas, culturales, entre otras, que inciden en un polisistema de inclusiones y exclusiones. El discurso crítico entonces suele morir bajo los efectos de su propio veneno.

En el siglo XIX, los resabios de un romanticismo defensor de la individualidad propiciaban lecturas histórico-biográficas e intervenciones impresionistas, pero pronto la idea de convertir el análisis literario en un trabajo prestigioso lo hizo doblegarse ante el positivismo comtiano, y esto propició la preocupación por una lectura "comprobable" (Redondo 1995: 4). La idea de convertir el quehacer crítico en un trabajo académico objetivo llevó a muchos a abrazar mecanismos estructurales inmanentes que negaron la figura del autor. Este deslizamiento en el enfoque constituye uno de los ejemplos que marcan el canon crítico.

Siguiendo la tipología de Alastair Fowler, los postulados teóricos que actúan en Costa Rica forman parte de un canon accesible (Harris 1998: 50), pues dadas las dificultades de acceso bibliográfico, los estudiosos costarricenses no siempre han tenido al alcance las teorías fundamentales. En algunos casos, como ocurrió con las teorías alemanas, parte del problema era encontrar traducciones disponibles. Por ello, muchas de las teorías impuestas en las universidades derivaban del canon personal del estudioso, cuyos discípulos, a su vez, repetían como la metodología legítima.

Una mirada diacrónica a través de los discursos crítico-literarios producidos en Costa Rica, destinados a enfrentar la literatura "propia", muestra una deriva axiológica de cordialidades y a veces también censuras poco sometidas a las rigurosidades teórico-metodológicas. Estas aproximaciones suelen ser depositarias de verosímiles estéticos, de retóricas de pertenencia nacional y de fuertes enfrentamientos ideológico-políticos.

Los modelos discursivos dilectos de esta práctica son, fundamentalmente, del dominio periodístico: gacetillas, reseñas "y otras cuantas ocurrencias que aparecían en los diarios nacionales" (Monge 1999: 28). Pero también se construyó, en buena medida, como recurso 
prologal, entre otros paratextos publicitarios propios de las portadas y contraportadas de los libros, aparte, desde luego, de las intervenciones publicitarias en los "bautizos" que buscan consagrar la obra en presentaciones iniciáticas.

La crítica literaria académica, promovida por especialistas universitarios, ha sido un trabajo fundamentalmente de las últimas décadas del siglo XX. Antes de este contexto, desde finales del siglo XIX, los estudios literarios eran sobre todo reseñas impresionistas y constituían una práctica esporádica que el comentarista combinaba con otros quehaceres. Por otra parte, cuando se configuran proyectos antológicos o se hacen inventarios literarios, prevalece la construcción del genio nacional como requisito de imagen frente al otro. El estudioso participa, de este modo, en la construcción de los imaginarios de pertenencia (Sandoval 2003: 9), que inciden en la formación del Estado-Nación. Mostrar el arte y demostrar con ello el espíritu cultural era más que una necesitad en el imaginario liberal y la ideología de la civilización ilustrada.

Tal es, al menos, la intención que motiva los primeros trabajos antológicos de poesía elaborados en Centroamérica. Esta misión estuvo a cargo de Félix Medina, quien, en 1873, bajo el título de Lira Nicaragüense, elaboró el primer compendio literario de Centroamérica ${ }^{1}$; de Román Mayorga Rivas, editor de Guirnalda salvadoreña (El Salvador 1884-1886); de Máximo Fernández, antologador de La lira costarricense (1890-1891)²; y de Rómulo E. Durón, quien editó Honduras Literaria en 1899. Guatemala y, lógicamente, Panamá (que aún no tenía estatuto nacional) fueron las excepciones en esta historia finisecular de apurarse a demostrar los valores literarios nacionales. Sin embargo, en el caso guatemalteco, se publicaron dos versiones antológicas con dimensión centroamericana. Lo único que se editó con identidad guatemalteca, a finales del siglo XIX, fueron dos compendios dedicados a biografías de literatos elaborados por Antonio Batres Jáuregui ${ }^{3}$.

La intención tácita, y a veces explícita, de estos proyectos fue consolidar una imagen del espacio nacional frente a los extranjeros, pero al mismo tiempo, a lo interno, se convirtieron en instituyentes fundamentales, pues iniciaron la canonización y la descatalogación de autores y obras, en los respectivos países. Estas antologías poéticas, entonces, fueron la primera tentativa de un trabajo crítico-historiográfico en función de lo nacional. Trascienden los linderos estéticos y asumen una dimensión política implícita en la proyección de la imagen local. Esta explicación coincide con los señalamientos de la crítica académica costarricense, a propósito de la antología de Máximo Fernández (Quesada 1986, Rojas y Ovares 1995 y Chen 1996). Estos estudiosos concuerdan en que La lira costarricense constituyó una primera formulación de lo nacional-literario.

La segunda parte de estos inventarios nacionales se dio a inicios del siglo XX, esta vez en el marco de un proyecto motivado desde afuera. Es la época de los parnasos hispanoamericanos, que se divulgan desde España mediante antologías editadas en Madrid y Barcelona. La primera es la de Nicaragua (1912), le sigue la de El Salvador (1916) y, finalmente, Costa Rica con una en 1920 y otra en $1921^{4}$. Los procesos constitutivos de los estados nacionales centroamericanos encuentran en estos inventarios un requisito básico del verosímil liberal: los altos valores de la cultura expresados a través del arte. En este sistema de representaciones, la poesía ocupa un lugar dominante, sobre todo a raíz de la consagración universal de Darío. Es por ello que las catalogaciones literarias se ocupan en estos primeros años únicamente del género lírico-poético. 
Sin embargo, el género discursivo que sustentó la discusión nacionalista fue particularmente el periodístico-ensayístico. Aparte de la cuantificación y catalogación de autores y obras, se elabora también un ideario estético para enjuiciar el discurso literario y un ideario de autenticidad nacional para legitimar las producciones.

La polémica nacionalista, iniciada en 1894 en Costa Rica, muestra cómo se tejía esta codificación. Carlos Gagini le cuestiona a Ricardo Fernández Guardia el estilo desarraigado de lo costarricense en el libro de cuentos Hojarasca. Fernández Guardia responde y acuña la famosa afirmación de que "De una parisiense graciosa y delicada pudo nacer la Diana de Houdon; pero vive Dios que con una india de Pacaca solo se puede hacer otra india de Pacaca" (cit. por Quesada 1986: 98). En la polémica intervienen Antonio Zambrana y Benjamín Céspedes. En 1900, Fernández Guardia asegura que, en esta polémica, él solo estaba defendiendo la libertad del escritor, pero que él está a favor del nacionalismo literario (Quesada 1986: 113).

En consecuencia, la crítica literaria naciente en Costa Rica pretende establecer un verosímil de identidad local. La función de la crítica en este contexto es modélica, prefigura un código estético, orienta y es normativa. En cierta forma, se coloca por encima de los discursos literarios y más que interpretativa es propositiva.

\section{Las primeras estéticas literarias: el trasluz del idealismo}

A finales del siglo XIX, un historiador nicaragüense, Tomas Ayón, establecía que solo el talento ilustrado era capaz de descubrir las variedades y los contrastes de la naturaleza y presentarlos con originalidad (Delgado 2001: 50). Es en la fragua de estas ideas donde la crítica costarricense encuentra la oportunidad de dar los primeros pasos. A finales del siglo XIX e inicios del XX, llegan a Costa Rica destacados pensadores que influyen en las ideas estéticas y políticas. Entre estos extranjeros destacan: Henri Pittier, Adolphe Marie, Lorenzo Montúfar, Máximo Jerez, los hermanos Fernández Feraz y Antonio Zambrana. Estos visitantes se involucran en la tarea divulgativa que desarrolla la literatura a través de las diferentes revistas y páginas literarias de los impresos periódicos. Además, participan de las discusiones epistemológicas y estéticas que inciden en el pensamiento literario de la época.

El jurista cubano, Antonio Zambrana, introdujo en Costa Rica las primeras ideas sobre estética literaria. Su ensayo Ideas de estética, literatura y elocuencia fue publicado en 1896 y sus planteamientos se convirtieron en el principal instituyente finisecular. "Era el poder tras el trono cultural" de la oligarquía intelectual costarricense (Barrantes 1994: 17). Llama a los escritores a ser auténticos y propone que la literatura debe tener una función persuasiva, que mueva a la fantasía y sensibilidad del auditorio. Según María Amoretti, los escritores de la época, como es el caso de Magón, adoptan estas ideas (2002: 182) e intentan jugar retóricamente con el lector.

Para Zambrana, el artista se distingue del hombre vulgar pues posee un talento especial:

Hay momentos en que por la agencia de misteriosos resortes, las facultades del artista se exaltan, llegan al colmo de su potencia, al apogeo de su eficacia: el artista entonces poseído por aquel demonio, por aquella furia de que nos habla Platón: está inspirado, decimos nosotros (1896: 18). 
Esta episteme coincide con el idealismo croceano y del impresionismo crítico francés, que desarrollaron Jules Lemaître, Anatole France y en alguna medida Émile Faguet, a partir de 1880 (Poulet 1997:13). Esta perspectiva permite abordar la literatura como un fenómeno creativo, donde el autor juega un papel fundamental en la construcción estética. Para Zambrana (1896: 38), la literatura es una interpretación ideal de la naturaleza por medio de la palabra, la cual "pinta también, no con los siete colores del arco iris, sino con los infinitos matices de la fantasía; cincela y dora las ideas, esculpe en magníficas estatuas la imagen de las grandiosas concepciones del humano genio".

Zambrana es, sin duda, un pionero de la teorización literaria en Costa Rica. Desglosa una tipología de la literatura con base en los modelos poéticos y prosaicos, a los que añade los dramáticos. Dedica un capítulo a explicar cómo se construye el estilo, que define como una fisonomía especial de los autores. La discusión sobre el estilo, como condición formal y no como contenido, lo lleva a discrepar de las tipologías tradicionales que se contentaban con categorías como sublime, medio o sencillo. Para él, el estilo es una cualidad que bien puede devenir en vicio, al abusar de ciertos procedimientos. La elevación, la seriedad o la melancolía de una producción no deben confundirse con el estilo; en este caso, se trata de una categoría literaria específica: el tono o nivel sentimental.

El filósofo costarricense, Moisés Vincenzi (1896-1963), continúa el trazado teórico zambraniano. Uno de sus primeros ensayos fue publicado originalmente en 1920 y se titula "Crítica trascendental". Entonces tenía solo 24 años, pero su ideario continuó a través de su vida, y en 1962, en uno de sus últimos libros de ensayos, retoma el tema, según él, desde una perspectiva mucho más madura. Una de las primeras observaciones que plantea es que el crítico joven se deja llevar por la opinión precipitada, mientras que el crítico maduro tiene la capacidad de explicar por qué valora de determinada manera una obra.

Vincenzi ve la crítica como un ejercicio en el que el estudioso debe comprometerse con seriedad. Se debe estudiar la obra desde la libertad, pero también desde una ética humana. Según él, existen dos tipos de crítica: por un lado está la aldeana y, por el otro, el modo civilizado. La crítica aldeana "es un desastre y es la más abundante de todas, ya que no solo la ejercen los ignorantes, sino muchos presuntos cultivadores del pensamiento" (1962: 50). La crítica civilizada permite mantener la armonía con el texto y para ello se requiere de un gran conocimiento. La crítica trascendental consiste en tomar la obra y explicar la dimensión estética, que es precisamente lo que la hace trascendente.

Otra publicación relevante en la dirección estético-literaria se da en mayo de 1925, cuando Rafael Estrada dicta una conferencia sobre estudios estéticos a la Asociación de Estudiantes Universitarios de Costa Rica. Establece una dicotomía entre comentario y crítica. Propone la crítica como un trabajo de construcción y el comentario, como destrucción.

Estrada rechaza el idealismo, y en consecuencia, niega la intuición como estrategia para acceder al arte. Propone en su lugar examinar las causas de los fenómenos artísticos. Para ello plantea que la estética debe ser ayudada por la Historia, de modo que se puedan hallar las causas históricas, y por la Psicología, para determinar "los móviles subjetivos del artista" (1926: 15). Con esta propuesta establece un proyecto interdisciplinario y considera el fenómeno artístico como un hacer en el que incide lo social (la historia) y lo individual (la psicología del autor). A este trabajo interpretativo se pueden unir otras disciplinas auxiliares, como la Métrica, la Armonía, la Estática y la Perspectiva. 
Según Estrada, cada especialista en Estética explica a su modo el fenómeno del arte. La estética ha estado subordinada a la filosofía y, por lo tanto, falta "una independencia razonable, enérgica, que le permita contemplar el fenómeno del Arte desde un mirador tan amplio como el del filósofo y el del artista" (1926: 13).

Entre los autores que Estrada cita se encuentra Benedetto Croce, pero recordemos que este teórico italiano es defensor de una propuesta idealista. Por lo tanto, las ideas que Estrada esboza en su conferencia parten más bien de la estética de Meumann, quien propuso una aplicación histórico-picológica para enfrentar el arte.

Sin embargo, las ideas croceanas siguen incidiendo en otras de las propuestas desarrolladas en este contexto. Buena parte de la episteme que guía el proyecto de los profesores de Estado se relaciona con estas ideas. Para los profesores de Español de secundaria, la función didáctica se adscribe a los criterios de la ilustración, que ven la literatura como el campo que permite otorgarle al ser humano la verdad cognitiva.

En esta tarea, destacan los profesores Rogelio Sotela, quien en 1920 publica Valores Literarios de Costa Rica, y Justo A. Facio, con sus ensayos "Carta Literaria", de 1918, y La cultura literaria, publicado originalmente en 1923.

Sin embargo, en la práctica, el idealismo se impuso sobre las demás posiciones y condujo, en contadas ocasiones, a retóricas cargadas de ocurrencias, lugares comunes y poses casi dramático-teatrales, tan elocuentes como esta de Ricardo Rojas Vicenzi, cuando abrió "la caja de pandora" para asomarse a las letras femeninas costarricenses, en su libro Crítica Literaria, de 1929:

\footnotetext{
Para hablar de las mujeres ilustres de mi tierra, me he rodeado de sedas y de pétalos (...) Fue menester iluminar la estancia con una semi-claridad de lirio mustio. (...) Así, fastuosamente, he vivido ante ellas; así, fantásticamente, fui exaltándome; y el eco de sus voces quebrándose sobre mi corazón y llenábame de misticismo. Fue de ese modo - de ese modo sólo entrevisto- que logré circunscribir mi pensamiento hacia las mujeres ilustres de Costa Rica (1929: 44).
}

Este supuesto ritual de sacralización y goce del momento consuntivo de las letras femeninas implica, al mismo tiempo, una descalificación desde el canon patriarcal, pues el texto adquiere un valor cosmético, y es por ello que el crítico se aproxima a él embelesado, desde la emoción contemplativa. El resto del artículo mantiene el mismo tono: "Se notan, sobre todo, tendencias al movimiento libre, como el pájaro que trina a gusto" (1929: 45). En cambio, cuando explica la obra de un varón, como en el caso de Joaquín García Monge, procede con mayor rigurosidad. Inicia con datos biográficos, ubica históricamente al autor e intenta situar las tendencias que sigue. Su crítica continúa aportando comentarios impresionistas, pero desde una perspectiva menos paroxística: "Lo curioso es que esta sensatez de García Monge es, en suma, la de Costa Rica, quintaesenciada en un hombre de líneas sobrias, como para esculpirlas" (1926: 31-2).

\section{Exorcizar la literatura: una tarea para docentes}

La literatura produce cambios ideológicos muy peligrosos en el lector, pero bien explicada en las aulas, con manuales educativos revisados y aprobados oficialmente, es capaz de encender goces estéticos únicos. No hay que olvidar que el arte es el producto de un genio 
nacional. Estos antagónicos preceptos, hoy tan viejos como el Diablo, inundaron los discursos académicos de los profesores, conferencistas y escritos críticos, de la primera mitad del siglo XX.

En 1916, en San Salvador, una organización obrera llamada “Gerardo Barrios" organizó una de las actividades más sui generis de la historia cultural centroamericana: un joven abogado salvadoreño, escritor, político y centroamericanista, dictó una conferencia cuyo tema era "La poesía costarricense". El auditorio, compuesto por un grupo de visitantes ticos, escuchó aquel homenaje salvadoreño a Costa Rica, quizá sin saber que aquel era uno los inventarios fundacionales de la crítica realista social en Centroamérica.

Salvador R. Merlos no era filólogo, aunque sí profesor universitario. Su alocución tiene como destino el consumo local y este propósito consuntivo orientará, en parte, el trabajo de los pedagogos centroamericanos de esta época, aunque no compartirían, por su contenido socialista, las ideas de fondo.

El modelo idealista croceano empieza a ser desplazado, justamente, en esa sala salvadoreña. En su lugar, se toma la vía de la complicidad con las organizaciones obreras, que promovían un destino de justicia social en Centroamérica, basado en los supuestos del materialismo dialéctico. En consecuencia, Merlos es una de las primeras voces críticas que deja de lado la función metafísica de la palabra poética y ve un proyecto político en el trasfondo de la palabra: "El poder social de las letras -apunta en la citada conferencia- es indiscutible y poderoso. ¿Quién puede negar que muchas de las novísimas orientaciones sociales no tuvieron su origen en las obras de Víctor Hugo y de Zola?" (1916: 15).

El destino de la literatura, como instrumento de transformación social, tendrá en la historia literaria de Centroamérica uno de los capítulos más extensos. Esta visión entusiasmará a las generaciones críticas, que se apurarán a divulgar la palabra literaria a través de publicaciones periódicas y conferencias. El caso más trascendente en Costa Rica fue Repertorio Americano, dirigido por Joaquín García Monge.

La vigencia del arielismo de Rodó y el programa antiimperialista constituyen otras de las motivaciones del proyecto de Merlos. Para él, los apetitos regionales fracturaron a Centroamérica, "para dar nacimiento a entidades pequeñas, que, débiles y desunidas, han empezado a sentir los efectos de su estado actual en cada zarpazo que sobre ellas descarga la República del Norte" (1916: 15).

Sin embargo, la propuesta arielista no logra la complicidad de la instituyente didáctica, la que se sigue adscribiendo, en general, a los criterios idealistas. Los profesores de esta época ven la literatura como un campo que permite otorgarle al ser humano la verdad cognitiva. Se niega, entonces, la posibilidad de asumirla como un dispositivo de trasformación.

Una vez expiado de sospecha y quizá después de alguna requisa ideológica, el texto y su autor pueden ser llevados al aula como modelos de genialidad. Rogelio Sotela, en un texto dirigido a estudiantes de primaria y secundaria, apunta:

\footnotetext{
La obra de un hombre, muchas veces, es el exponente de la cultura de un país; y Costa Rica, con ser un país tan joven, tiene un buen grupo de hombres que le han dado su anhelo y su saber y que han sido ejemplo de una vida superior de cultura y de carácter. Nosotros debemos conocer esas vidas (1938: 6).
}

Estas biografías modélicas para niños muestran cómo el sistema estatal, en este caso, acude al crítico para que este seleccione y oriente, de modo que sea posible controlar la circulación literaria. 
Después de Valores Literarios de Costa Rica, Rogelio Sotela desarrolla la primera sistematización generacional en Costa Rica, publicada originalmente en 1923, bajo el título de Escritores y poetas de Costa Rica. Plantea cuatro generaciones básicas, con base en las fechas de nacimiento de los autores. Los primeros son los nacidos hacia el año 1860. "La segunda la componen los hombres que nacieron cerca del año 1875; la tercera los que nacieron del 80 al 85 y la cuarta los que nacieron hacia 1900" (1938: 5). Incluye además una generación que denomina "Los Nuevos", donde se ubican los nacidos de 1910 a 1915.

Justo A. Facio, por su parte, representa uno de los primeros aportes significativos orientados a escudriñar la identidad nacional. En el texto "Carta literaria", desarrolla una tipología literaria en términos de literatura regionalista y psicologizante. En la primera, se inscribe lo referente a lo nacional y en la segunda, lo exótico. De acuerdo con Ovares y otros, este trabajo

como visión temprana del panorama literario nacional, entrecruza las nociones de género tradicionales, con la idea de un crecimiento de Costa Rica, planteado en términos más biológicos que históricos, bajo la analogía país/individuo. En este sentido, la primera conclusión que puede obtenerse sobre el modo cómo Facio observa la literatura nacional tiene dos aspectos interesantes: lo nacional no está acabado, es joven y, por lo mismo, su consolidación se halla en el futuro (1993: 13).

En esa misma vertiente pedagógica se inscriben los trabajos de León Pacheco, que inició con una serie de análisis sobre la obra de Rafael Cardona (1919) y Moisés Vincenzi (1920), entre otros.

Otro escritor y crítico que prepara textos pedagógicos, en ese contexto, es Roberto Brenes Mesén, y aunque lo hace desde la plataforma editorial de Joaquín García Monge, sustenta el ideario trascendental de la metafísica. Para él, "en el arte literario, una expresión de belleza es también una eterna alegría” (Brenes 1922: 5). Sin embargo, Brenes Mesén, a diferencia de los docentes de Estado de la época, produjo uno de los trabajos críticos más significativos en relación con la literatura americana. De hecho, su trabajo es pionero en los estudios con vocación latinoamericana. Es por ello que su gesto, en este sentido, coincide con el arielismo.

\section{En conclusión}

Queda claro, hasta aquí, y sobre todo con el libro de Rojas Vincenzi, que el canon es una construcción desde el poder simbólico (patriarcal, oligárquico, académico), y que la crítica costarricense, que surgía a inicios del siglo XX, impulsada por Zambrana, disponía básicamente de las epistemes defensoras del estilo y la genialidad de los autores. No existía, sin embargo, otro requisito aparte del gusto, para determinar el valor estético. Esta fue la principal fisura de dicho proyecto estético. Es Rafael Estrada, con la introducción de meumannianas, el primero que logra desmarcarse de esta episteme, pero sus ideas habrían de esperar aún muchos años antes de que se consideraran como una fórmula válida para enfrentar el discurso literario.

El discurso oficial de los programas educativos gubernamentales, a inicios del siglo $\mathrm{XX}$, no acepta la función "cuestionadora" de la literatura e intenta resolver el dilema a través de la idea de que el goce estético es en sí lo social. Este ideario propone que los seres humanos tienen tres grandes aspiraciones: la verdad, el bien y la belleza. "A la primera se llega por 
la ciencia; a la segunda, por la virtud; a la tercera, por el arte. Las tres representan, en conjunto, el desenvolvimiento de las facultades humanas en sus tres principales aspectos: la inteligencia, la voluntad y el sentimiento" (Zamora 1931: 4). El efecto sentimental de la palabra artística combate, de este modo, las tesis del socialismo realista. La literatura no afecta intelectivamente. Cuando ocurren efectos sociales, como en el caso del wertherismo y los suicidios, estos se dan porque a veces la literatura puede pervertir los sentimientos. Dicho de otro modo, la literatura influye en los estados de ánimo, generalmente para gozo, pero también -advertencia tácita- puede envilecer a los lectores. No en vano, el manual didáctico donde se encuentran estas ideas se llama orientación literaria, en vez de preceptiva, y fue acogido como texto oficial educativo por decreto gubernamental en $1929^{5}$.

Los liberales no enuncian un imaginario esencial de la nación. Su preocupación es más la articulación de un proyecto político nacional: inserción económica, educación, etc. Esto explicaría por qué la mayoría de los estudios literarios hechos por los liberales están más orientados hacia los públicos estudiantiles internos.

La orientación metafísica trasciende en la crítica literaria más allá de estos epistemes fundacionales. Como muy bien lo anota Alexander Jiménez, en la Historia de la Literatura Costarricense de Abelardo Bonilla, se omite con "naturalidad" la literatura de otros sectores étnicos del país, como la indígena o la afrocaribeña. Bonilla afirma que, desde sus inicios, en la literatura costarricense predomina el pensamiento y lo conceptual más que lo poético. Entre otras razones, esta racionalidad se debe a "la superioridad numérica y cultural de la raza blanca sobre la india mestiza" (1967: 34).

Sin embargo, este proyecto metafísico terminará por desplomarse frente a las teorías interpretativas de orientación materialista, y el "ser nacional” se indagará entonces más allá de la ilusión idílica con la que miraban los primeros estudiosos de la literatura en Costa Rica.

\section{Notas}

1. Esta primera antología se propone como una colección de los mejores ensayos de los poetas nicaragüenses. Medina incluye 6 poetas y consigna 18 poemas (Chinandega: Imprenta "Del Progreso". 1873. 43 p.) Un trabajo más ambicioso, desde el punto de vista de la divulgación de los valores literarios nacionales en Nicaragua, es la antología de Alberto Ortiz, Parnaso Nicaragüense, publicada en Barcelona en 1912, como parte de un proyecto mayor que en su momento también incluyó a otros países.

2. Máximo Fernández anota, en el prólogo de la antología, que en una revista extranjera donde se hacía referencia a los progresos de la literatura centroamericana, se dijo que en Costa Rica no se cultivaba la poesía sino únicamente el café (1990: xii). De ahí que esta publicación sea una respuesta para desmentir la "afrentosa" afirmación.

3. Se trata de los libros: Literatos guatemaltecos. (Landívar e Irrisari) Guatemala: Tipografía Nacional, 1889, y Biografías de literatos guatemaltecos. Guatemala: Academia Guatemalteca Correspondiente a la Real Academia Española: 1889.

4. Los datos bibliográficos de estas publicaciones fueron señalados por Eduardo Arellano en la información bibliográfica que consigna al final del Diccionario de Autores Centroamericanos (2003). Las referencias son las siguientes: Alberto Ortiz. 1912. Parnaso nicaragüense. Antología completa de sus mejores poetas. Barcelona: Maucci. 253 p. (30 poemas y 137 poetas); Salvador L. Erazo. 1917. Parnaso salvadoreño. Antología esmeradamente seleccionada de los mejores poetas de la República de El Salvador. 
Barcelona: Maucci. 303 p. (34 poetas y 164 poemas); Eduardo de Oray. 1920. Los mejores poetas de Costa Rica. Madrid: Compañía Ibero-Americana de Publicaciones. 304 p.; Rafael Bolívar Coronado. 1921. Parnaso costarricense. Selección esmerada de los mejores poetas de Costa Rica. Barcelona: Maucci. 207 p. (15 poetas y 89 poemas).

5. Según consta en la portada de la segunda edición de 1931, que es la que estamos utilizando.

\section{Bibliografía}

Amoretti H., María. 2002. Magón... la irresistible seducción del discurso. San José: Editorial Perro Azul.

Bakhtin, Mikhail. 1986 Problemas literarios y estéticos. Trad. de Alfredo Caballero. La Habana: Editorial Arte y Literatura.

Bonilla Abelardo. 1967. Historia de la literatura costarricense. 2 ed. San José: Editorial Costa Rica.

Brenes Mesén, Roberto. 1936. Crítica americana. San José: Ediciones del Convivio.

Estrada, Rafael. 1926. Sobre los estudios estéticos. San José: Imprenta Alsina.

Facio, Justo A. 1930. La cultura literaria. 2da. Edición. San José: Imprenta Alsina.

Harris, Wendell V. 1998. "La canonicidad”. En El Canon Literario. Madrid: Arco/libros. S.L.

Merlos, Salvador R. 1916. La poesía en Costa Rica. San Salvador: Imprenta Nacional.

Monge, Carlos Francisco. 1992. Antología de la poesía de Costa Rica. San José: Editorial de la Universidad de Costa Rica.

Ovares, Flora et al. 1993. La casa paterna. Estructura y nación en Costa Rica. San José: Editorial Universidad de Costa Rica.

Pacheco, León. 1954. "El costarricense en la literatura nacional" Revista de la Universidad de Costa Rica. № 10: 75-141.

Poulet, Georges. 1997. La conciencia crítica. De Madame de Staël a Barthes. Trad. Carlos Piera y Roberta Quance. Madrid: Gráficas Rógar, S.A.

Quesada Soto, Álvaro. 1986. La formación de la narrativa nacional costarricense (18901910). Enfoque histórico social. San José: Editorial UCR.

Rojas Vincenzi, Ricardo. 1929. Crítica literaria. San José: Imprenta Borrasé, hnos. 
Sotela, Rogelio. 1938. Literatura costarricense. Antología y biografías. 3ra. Ed. San José: Imprenta Lehmann.

Sullá, Enric. 1998. "El debate sobre el canon literario". En El Canon Literario. Madrid: Arco/libros. S.L.

Urlich Gumbrecht, Hans. 1998. "Cual Fénix de las cenizas” o del canon a lo clásico” En El Canon Literario. Madrid: Arco/libros. S.L.

Vincenzi, Moisés. 1962. Bandera Blanca. Ensayos y páginas dispersas sobre crítica de arte. San José: Editorial Lehmann.

Zambrana, Antonio. 1896. Ideas de estética, literatura y elocuencia. San José: Tipografía Nacional. 